\title{
Uma ferramenta de planejamento de estudos para concursos
}

\author{
Leonardo Pimentel ${ }^{1}$ \\ Kele Belloze ${ }^{1}$, Jorge Soares ${ }^{1}{ }^{2}$ \\ Eduardo Ogasawara ${ }^{1}$ \\ Renato Mauro ${ }^{1}$
}

\begin{abstract}
Resumo: De acordo com a constituição brasileira, a única forma de se tornar um empregado do governo é passar em um concurso público. O exame de conhecimento do cargo é um dos componentes mais importantes de um concurso. Estudar para esse exame é uma tarefa que requer planejamento. Um meio de obter um bom planejamento é construir uma grade de horários que relacione as matérias a serem estudadas com os respectivos horários disponíveis para o estudo. Esse tipo de problema se assemelha bastante à gerência de projetos, em que se procura estabelecer a distribuição das atividades ao longo do tempo disponível. Assim, torna-se interessante explorar a dinâmica de estudos para concursos como um projeto. O presente trabalho apresenta a ferramenta de apoio ao estudos Passe-me, baseada no ciclo PDCA (do inglês, Plan - Do - Check - Act). Por se tratar de uma ferramenta web, o tempo de resposta para produzir uma grade de estudos é fundamental. A ferramenta faz uso de algoritmo genético para calcular a grade de horários priorizando a velocidade de resposta. A ferramenta foi avaliada em diferentes cenários de uso e obteve desempenho satisfatório durante a produção da grade de estudos.
\end{abstract}

Palavras-chave: Algoritmos genéticos. Ciclo PDCA. Concurso Público. Grade de horários.

\begin{abstract}
According to the Brazilian Constitution, the only way to become a public employee is passing a public exam. The job-knowledge exam is one of the most important components of a public exam. Studying for such exam is a challenging task that requires planning. An important activity during planning is to build a timetable that conciliates all subjects that need to be studied with the available time for studying them. This problem is very similar to project management, where the focus is on distributing activities through available time. Thus, it becomes interesting to address the problem of studying for public exam as a project. This paper presents Passe-me, a tool to support studying based on PDCA (Plan -Do - Check-Act) project lifecycle. Since Passe-me is a web tool, its response time for displaying a timetable for studying is crucial. The tool uses genetic algorithm to compute the timetable prioritizing response time. The tool was evaluated under different scenarios and obtained satisfactory performance during timetable generation.
\end{abstract}

Keywords: Genetic algorithms. PDCA cycle. Public Exam. Timetable.

\section{Introdução}

Muitos brasileiros priorizam os concursos públicos como o caminho para a realização profissional e sobrevivência econômica. Nesse sentido, esses brasileiros buscam por características como a estabilidade, a objetividade do processo de admissão, os salários mais atraentes e maior respeito às questões trabalhistas. A necessidade desse método de seleção advém de três fatores: (i) a necessidade do Estado em ampliar seus quadros de pessoal; (ii) a redução e a extinção de formas precárias de contratação, como as terceirizações e o nepotismo; e (iii) a aposentadoria dos atuais servidores [1].

${ }^{1}$ Centro Federal de Educação Tecnológica Celso Suckow da Fonseca (CEFET/RJ)

\{kele.belloze, jsoares, rmauro\}@cefet-rj.br, eogasawara@ieee.org

${ }^{2}$ Universidade do Estado do Rio de Janeiro (UERJ)

http://dx.doi.org/10.5335/rbca.2015.4506

Revista Brasileira de Computação Aplicada (ISSN 2176-6649), Passo Fundo, v. 7, n. 3, p. 17-30, out. 2015 
Segundo Pimentel [2], presidente da Associação Nacional de Proteção e Apoio aos Concursos (Anpac), em um país como o Brasil, que apresenta alta rotatividade de mão de obra, somente uma formação sólida não garante sucesso contra o temido desemprego. Ele cita que este cenário de demissões e competitividade elevada no mercado de trabalho ajudou a levar grande parte da juventude brasileira - e não somente ela - aos cursos preparatórios presenciais, tele-presenciais e on-line, em busca da tão sonhada “estabilidade". É visível a existência da "indústria dos concursos", criada para tratar a grande demanda de pessoas querendo se preparar para ocupar um emprego público. Para se ter ideia da dimensão que essa indústria tomou, pesquisas apontam que ela chega a movimentar $\mathrm{R} \$ 50$ bilhões por ano [3].

Esse interesse cada vez maior pelos certames têm algumas consequências relevantes, como a maior atenção que é dada ao ensino a distância, que oferece algumas vantagens significativas em relação à modalidade presencial, como a redução de custos e a maior autonomia do aluno. Sites oferecendo cursos e materiais para concursos, tendo como base esta modalidade de ensino, proliferaram-se em grande quantidade para atender a essa demanda dos estudantes, os chamados "concurseiros" ou "concursandos", como são popularmente conhecidos .

No geral, cada estudante tem sua própria metodologia e usa as ferramentas que acha mais conveniente para organizar seus estudos. Alguns dispensam o uso de qualquer método ou ferramenta, trazendo para si a responsabilidade de administrar seu tempo com base na memória. Sem a utilização de métodos e hábitos produtivos temos a tendência a cair em armadilhas, como a procrastinação, a falta de organização, motivação e concentração. Isto resulta em um acúmulo de estresse, improdutividade e sensação de tempo perdido.

Quando se pensa em preparação para um concurso, alguns podem pensar que saem na frente aqueles que têm mais disponibilidade de tempo ou estudam com mais afinco, mas, na realidade, não acontece exatamente assim. Uma preparação adequada não está associada somente ao estudo em abundância. Ela requer diversas etapas que podem ser seguidas como um ciclo, a fim de se obter um aproveitamento satisfatório [4]. Esse tipo de problema é comumente abordado pela área de gerência de projetos. Essa área procura estabelecer uma boa distribuição das atividades ao longo da duração de um projeto. Sendo assim, torna-se interessante abordar o processo de estudos como um projeto. O ciclo PDCA (Planejar - Executar - Verificar - Agir, do inglês: Plan - Do - Check - Act) é um exemplo de abordagem bastante utilizada pela área de gerência de projetos para resolver problemas, pois permite o acompanhamento e melhoria contínua do processo como um todo, identificando os possíveis problemas e sanando-os [5].

Além de um acompanhamento contínuo do processo de estudo, a administração do tempo também é necessária $[6,7,8,9]$. Quanto mais escasso o tempo, maior deve ser o controle a ser exercido sobre ele de forma a atingir resultados mais satisfatórios. Uma característica geral presente nos projetos é que o controle sobre o tempo acaba resultando no desenvolvimento de um cronograma que deve ser seguido para atingir um planejamento. A partir de uma pesquisa realizada por Pinheiro [1], foi possível constatar que os estudantes consideravam o planejamento de estudos como importante. Ao mesmo tempo, esses estudantes não o realizavam da forma adequada.

Para se preparar para um concurso, o tempo é um dos principais recursos. Há a necessidade de se estudar o conteúdo programático dos exames dentro do prazo do concurso. No âmbito do planejamento de estudos, é muito comum que uma grade de horários seja construída relacionando as matérias a serem estudadas com os respectivos horários disponíveis do estudante. Um dos maiores problemas para o estudante é, então, produzir uma grade de horários para estudo que seja compatível com sua disponibilidade de horários e o conteúdo programático que deve ser estudado.

Este trabalho apresenta a ferramenta Passe-me, baseada no ciclo PDCA, cujo objetivo é gerenciar os estudos do usuário, apoiando-o no aumento da produtividade no que tange ao tempo necessário para a preparação para um exame. Para tal, a ferramenta propõe-se a realizar o planejamento adequado dos estudos do usuário durante o tempo que este deseja desprender, produzindo uma grade de horários das matérias a serem estudadas nos tempos disponíveis do estudante. Por se tratar de uma ferramenta web, o desenvolvimento prioriza a produção de grades de horários versáteis em tempo hábil, utilizando para este fim uma abordagem baseada em algoritmos genéticos. A ferramenta apresenta outras características como: gerenciamento e catálogo dos materiais necessários para atingir o escopo do projeto; o monitoramento do andamento do projeto de acordo com o cronograma inicial, fornecendo flexibilidade para possíveis desvios; e o controle do tempo gasto em cada etapa.

Além dessa introdução, este trabalho está organizado em mais cinco seções. A seção 2 descreve os conceitos que foram utilizados no desenvolvimento deste trabalho, como os conceitos relacionados à área de gerenciamento 
de projetos e a abordagem de algoritmo genético utilizada para o desenvolvimento da grade de horários. A seção 3 apresenta os trabalhos relacionados. A seção 4 descreve como os conceitos listados no referencial teórico são aplicados no contexto da ferramenta Passe-me, assim como os aspectos técnicos mais relevantes da ferramenta. A seção 5 apresenta a avaliação experimental realizada com a ferramenta, onde se foca na geração da grade de horários. Por fim, a seção 6 expressa as conclusões do trabalho.

\section{Planejamento de estudos para concursos baseado em projetos}

Um projeto é definido como um esforço ou empreendimento temporário a fim de criar um produto, serviço ou resultado exclusivo. Sua característica temporária advém do fato de ter início e término definidos, sendo este término alcançado quando seus objetivos iniciais são atingidos satisfatoriamente, ou quando da conclusão da impossibilidade da consecução desses mesmos objetivos, ou até mesmo quando os objetivos perdem sua utilidade, não sendo mais o projeto necessário [10, 11, 12].

O processo de estudo objetivando a aprovação em um concurso também é um esforço temporário, pois possui início e término definidos. O início corresponde ao momento em que o estudante começa a realizar o planejamento de estudos, e o término se dá quando a aprovação ou reprovação no concurso é obtida. Esse término é o resultado singular desse processo de estudo. É o resultado de como foi feito o planejamento de estudos e de como ele transcorreu rumo aos objetivos. Dessa forma, o processo de estudo pode ser visto como um projeto, aproveitando-se da área de gerenciamento de projetos cuja importância se apresenta consolidada tanto na academia quanto no mercado. Cabe ressaltar que essa correspondência a projeto pode ser aplicada a qualquer processo de estudo, não necessariamente com o fim de obter a aprovação em um concurso público.

A analogia do estudo para concursos como um projeto é algo que vem sendo desenvolvido por autores de livros voltados para a preparação do estudante para concursos públicos, uma vez que o planejamento e a administração do tempo são praticamente uma constante neste tipo de literatura. Alguns autores, como Pinheiro [1, 13] fazem uma analogia direta usando conceitos de gerenciamento de projetos e planejamento estratégico aplicados à preparação para concursos. Outros, como William Douglas [14, 15] e Meirelles [4], usam alguns conceitos da área de gerenciamento de projetos, apesar de não fazerem uma analogia direta.

A natureza exclusiva dos projetos pode gerar incertezas quanto aos produtos, serviços ou resultados criados por esses. Por exemplo, a equipe do projeto pode não ter o conhecimento necessário demandado pelo projeto, o que acarretaria na necessidade de treinamentos [12]. Da mesma forma, há incertezas também em um projeto de estudos. Em relação ao planejamento, por exemplo, pode-se citar incertezas relativas à estimativa da duração do estudo das matérias. A falta do conhecimento dos assuntos, da administração de tempo e da produtividade pode fazer com que o estudante crie estimativas irrealistas que podem comprometer o planejamento. O não conhecimento das técnicas de estudo mais adequadas para cada matéria e dos períodos do dia em que há maior atenção e concentração, faz com que se use métodos de estudo inadequados. Além disso, ainda pode-se citar fatores como interrupções externas, a organização do ambiente de estudo e a conciliação de outros compromissos e atividades pessoais. Esses são só alguns dos fatores que aumentam o grau de incerteza em um processo de estudo.

Dessa forma, é a partir desses fatores ou incertezas que os riscos do projeto se potencializam. Para mitigar esse grau de incerteza, e consequentemente o risco do estudo, é essencial que haja um planejamento estruturado e meios de acompanhar a execução do estudo de forma a identificar e resolver rapidamente as deficiências que possam surgir. Uma forma de obter esse planejamento é aplicar um processo bem estabelecido (seção 2.1) que atue diretamente na administração do tempo (seção 2.2) e que se traduza no estabelecimento de uma grade de horários para estudos (seção 2.3).

\subsection{Ciclo PDCA}

Com a estruturação dos estudos na forma de um projeto, deve-se adotar um processo que seja simples e ao mesmo tempo flexível para apoiar a modelagem, o desenvolvimento e a evolução do projeto de estudos do estudante. Isso engloba diminuir a incerteza do projeto por intermédio das fases de monitoramento e ação, que permitem, respectivamente, identificar e corrigir as possíveis irregularidades no planejamento.

O ciclo PDCA (Planejar - Executar - Verificar - Agir, do inglês: Plan - Do - Check - Act), também

Revista Brasileira de Computação Aplicada (ISSN 2176-6649), Passo Fundo, v. 7, n. 3, p. 17-30, out. 2015 
conhecido como ciclo de Deming, foi um trabalho pioneiro na área de gerenciamento de qualidade, sendo uma ferramenta poderosa no controle do processo de solução de problemas [5]. Esse ciclo pode ser usado por qualquer projeto que tenha como objetivo a melhoria contínua. Ele é usado por empresas do mundo todo nas mais diversas áreas.

Conforme é possível observar na Figura 1, as quatro etapas que compõem o ciclo são encadeadas e dependentes entre si. A etapa Planejar consiste na identificação dos objetivos e metas a serem alcançados em cada etapa do processo. A etapa é dita finalizada quando se estabelece o caminho e os métodos a serem usados para se atingir o objetivo. A etapa Executar realiza o que foi definido na fase de planejamento, coletando dados sobre a execução das tarefas. A etapa Verificar monitora e analisa o que está sendo feito, confrontando o executado frente ao planejado. Nessa etapa, consolida-se os resultados em relatórios de desempenho, a fim de identificar possíveis melhorias no processo. A etapa Agir desempenha ações corretivas e preventivas, de forma a resolver ou evitar os problemas identificados nas etapas anteriores. Sendo assim, essas etapas se agrupam em um ciclo, de forma a conduzir os esforços em uma estrutura organizada e coordenada, visando à melhoria contínua.

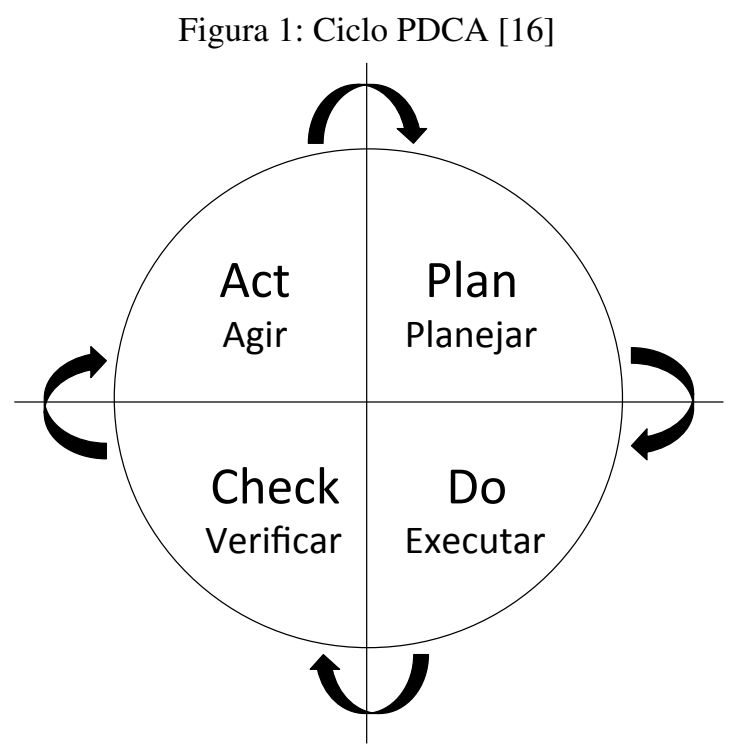

\subsection{Administração do tempo}

O conceito de administração do tempo está presente em diversas áreas e não somente na literatura voltada à preparação para concursos públicos. Walsh [17] alega que técnicas de administração de tempo são essenciais no gerenciamento de projetos, sendo o tempo considerado um importante recurso. Na perspectiva dos estudantes, a gerência do seu próprio tempo é um dos maiores desafios encontrados por eles [7, 8]. Segundo Wong [9], o gerenciamento de tempo aliado à definição de objetivos é uma das técnicas de estudo mais essenciais, pois é por meio delas que se torna possível estruturar o uso de outras técnicas de estudo. De fato, não há como se estudar apropriadamente sem a alocação do tempo necessário para que o processo ocorra sem interrupções e de forma produtiva. O estudo eficaz requer uma quantidade significativa de tempo que deve ser desprendido, sendo melhor aproveitado quando se aloca tempo exclusivo para o processo.

O ritmo de estudos pode ser imposto ao estudante por algum tutor, na medida em que há uma data definida para os trabalhos ou exames, ou o estudante pode ter a liberdade de escolher seu próprio ritmo de estudo [8]. No caso dos concursos públicos, é possível afirmar que os dois ritmos acontecem em fases distintas, dependendo de cada caso. No geral, um estudante tem liberdade para definir seu próprio programa e ritmo de estudo de acordo com suas prioridades e objetivos, a não ser que o mesmo delegue isso para outra pessoa (tutor), como geralmente acontece no caso dos cursos preparatórios. Porém, a partir do momento que ele decide realizar um determinado concurso público com a data do exame definida, ele se vê com um prazo inadiável para finalizar seus estudos que, nesse caso, é imposto pelo próprio concurso. 
Independente do ritmo ou programa de estudo, é necessário que haja planejamento [8]. Esse planejamento se traduz no estabelecimento de uma grade de horários. Ele se torna necessário a partir do ponto em que oferece uma direção e mostra o caminho a ser percorrido para atingir um dado objetivo. A maioria dos problemas relativos ao gerenciamento do tempo é causada pelo fato do estudante não ter planos, ou, quando os têm, são irrealistas e/ou vagos [7]. Segundo Pinheiro [13], o estabelecimento de um planejamento voltado à preparação para o concurso público ou exame oficial também tem o papel de colaborar com o estudante no sentido de: (i) proporcionar senso de direção; (ii) permitir o controle do desenvolvimento do plano traçado; (iii) permitir a definição do foco na execução do planejamento.

\subsection{Otimização de grades de horários}

O problema de criação da grade de horários se enquadra numa classe de problemas denominada NP-difícil que se tornam muito difícil de solucionar à medida que seu tamanho aumenta. Além disso, a grade de horários precisa ser continuamente revista durante cada etapa do ciclo PDCA. Outro aspecto importante é que a função objetivo deve ser parametrizada pelos aspectos do estudante. Assim, torna-se necessária a aplicação de abordagens baseadas em heurísticas que sejam versáteis na especificação dos parâmetros da função objetivo, como algoritmos genéticos, para obter respostas adequadas ao problema da elaboração das grades de horários.

Os algoritmos genéticos são algoritmos que pertencem à área da computação evolutiva [18]. Essa área se preocupa com o desenvolvimento de sistemas adaptativos mediante a análise de problemas que se assemelham a versões simples dos processos e mecanismos da evolução, possuindo a teoria da evolução de Darwin como principal fonte de inspiração. Algoritmos ditos evolucionários compartilham propriedades adaptativas por meio de um processo iterativo que acumula e amplifica variações benéficas empregando tentativa e erro. Soluções candidatas representam membros de uma população virtual que lutam pela sobrevivência em um ambiente modelado a partir de uma função objetivo específica ao problema [18].

\section{Trabalhos relacionados}

A geração de grades de horários é encontrada na literatura principalmente como um desafio para instituições de ensino, que se veem a cada ano ou período de curso com a tarefa de criar uma nova grade de horários respeitando a disponibilidade de pessoal, as restrições e os recursos disponíveis. Os algoritmos genéticos são uma abordagem que tem sido bastante utilizada para resolver o problema da grade de horários neste domínio. Abbaszadeh e Saeedvand [19] apresentaram um algoritmo genético que pretende trabalhar com alta eficiência e precisão considerando o máximo de restrições no planejamento da grade de horários. Dessa forma, é determinado o horário de início e término para cada grade e em seguida a mesma é dividida em intervalos de tempo menores. Os autores consideram que o planejamento da grade de horários é feito com eficiência e velocidade aceitáveis, utilizando esse método. Innet [20] propôs um modelo de algoritmo genético adaptativo para melhorar a eficácia da organização automática da grade de horário. Mousa e El-Sisi [21] propuseram um projeto e implementação de uma ferramenta para geração da grade de horários baseado em algoritmo genético utilizando combinações diferentes de algoritmos de seleção e tipos de mutação. Além destes, há trabalhos que apresentam uma combinação de algoritmos genéticos com outras abordagens como busca tabu [22] e anelamento simulado [23], também com a finalidade de gerar uma grade de horários mais rápida e eficiente.

Os trabalhos citados consideraram a criação e a geração de uma grade de horários para resolver um problema relacionado à instituições de ensino e não a um planejamento de estudos. Contudo, os resultados indicaram um bom caminho na utilização deste tipo de algoritmo para geração de grades de horários visando esse fim. Ademais, não foram encontrados trabalhos na literatura que descrevessem um planejamento e geração automática de grade de horários baseada no ciclo PDCA.

Existe uma outra categoria de trabalhos relacionados, vinculadas às ferramentas de apoio a concurso. A ferramenta Tuctor [24], é voltada à montagem, à implementação e ao controle da execução de um plano de preparação para concurso. Ela divide o processo de preparação em duas fases distintas. Na primeira fase, há a construção e consolidação das bases de conhecimentos. Para isso, são usados ciclos semanais de estudo, definidos a partir do levantamento do tempo disponível em cada dia da semana e seus respectivos turnos. Após a disponibilização de horários e as matérias necessárias, é feita a alocação nesses horários segundo critérios de importância, facilidade 
e alternância das matérias. Existe também a possibilidade de alocar automaticamente as matérias na grade de horários. Na segunda fase é realizado um aprofundamento e consolidação do conhecimento assimilado na primeira fase, de forma a aperfeiçoar e manter esse conhecimento obtido e suprir deficiências deixadas. Apesar de se apresentar como uma boa ferramenta, a Tuctor não adota um modelo baseado em projetos, o que não estimula a avaliação dos problemas encontrados e a melhoria contínua. Além disso, o prazo para o aprendizado em tempo hábil não é considerado.

\section{A ferramenta Passe-me}

A ferramenta Passe-me tem como objetivo gerenciar o processo de estudos para um concurso. É uma ferramenta web cujo desenvolvimento é baseado no ciclo PDCA para organização das etapas de estudo e no uso de algoritmos genéticos para geração otimizada da grade de horários. Nesse sentido, as etapas componentes para o desenvolvimento da ferramenta são apresentadas nas subseções a seguir.

\subsection{Metodologia baseada em PDCA}

A metodologia baseada no ciclo PDCA aplicada no desenvolvimento da ferramenta conduz o usuário no seu planejamento de estudos. Contudo, é importante destacar que o conceito de ciclo não é apresentado explicitamente ao usuário, ou seja, nem o ciclo e nem seu funcionamento são descritos para o usuário. Ele é trabalhado de forma sutil no contexto de implementação da ferramenta, fornecendo os itens necessárias nos momentos oportunos e impedindo que certas tarefas sejam executadas antes de outras. Dessa maneira, é possível visualizar o planejamento que foi estruturado, o tempo alocado para cada atividade durante a etapa de execução e a aplicação de melhorias por meio de ações corretivas. A seguir, são descritas como as etapas do ciclo PDCA são trabalhadas na ferramenta.

\subsubsection{Planejamento}

O objetivo da fase de planejamento é produzir uma grade de horários que possa ser seguida pelo usuário. A etapa de planejamento inclui algumas atividades: (i) levantamento dos insumos, (ii) levantamento do escopo, (iii) definição de revisões e (iv) decomposição em tarefas. Na atividade de levantamento dos insumos, o usuário deve alimentar a ferramenta informando dados básicos que são essenciais ao planejamento do estudo. Além disso, as matérias, as fontes de estudo e os grupos de matérias podem ser reutilizados em diversos planejamentos diferentes, não sendo necessário cadastrar esses dados a cada grade de horários que se deseja criar. Na atividade do levantamento do escopo, o usuário preenche um "passo-a-passo" no qual lhe é solicitado informações como: nome da grade, seu objetivo, data de início e término, seus horários disponíveis na semana para estudo e as matérias e fontes de estudos a serem utilizadas na grade. Na atividade de definição de revisões, o usuário sinaliza que o estudo tem revisões, indicando seus respectivos dias e horários, e a ferramenta se encarrega de criá-las e associálas ao novo evento de estudo criado. Essas revisões são imprescindíveis para reforçar as conexões e consolidar o conteúdo estudado na memória. Na atividade de decomposição em tarefas, a ferramenta disponibiliza ao usuário uma funcionalidade para gerenciamento de suas tarefas. Cada tarefa possui um nome, um estado indicando se está completa ou não, e uma data de expiração opcional que, caso seja preenchida, é usada pela ferramenta para lembrar ao usuário quando a tarefa estiver perto do seu vencimento ou caso já esteja vencida.

\subsubsection{Execução}

É nesta fase do ciclo que o estudo propriamente dito ocorre. A ferramenta disponibiliza um calendário para que o usuário possa verificar o que tem de ser estudado em cada dia. O calendário é interativo, ou seja, novos eventos de estudo podem ser incluídos, e os eventos cadastrados podem ser alterados ou excluídos. A partir da funcionalidade de acompanhamento, é possível visualizar o que falta estudar em um período e indicar a conclusão de um evento de estudo. Na conclusão de um evento, deve ser informado se ele foi estudado conforme o planejado ou não. Em caso positivo, a ferramenta adiciona o tempo estudado no evento ao total já estudado pelo usuário; em caso negativo, deve ser informado o motivo de não ter estudado conforme o planejado e quanto tempo foi de fato dedicado a esse.

Revista Brasileira de Computação Aplicada (ISSN 2176-6649), Passo Fundo, v. 7, n. 3, p. 17-30, out. 2015 


\subsubsection{Análise}

O objetivo dessa etapa é fornecer dados que possam embasar qualquer melhoria que o usuário decida realizar no seu planejamento. Na ferramenta, há uma seção separada na qual o usuário pode visualizar alguns relatórios que apresentam o seu progresso, como: motivos para não estudar, relação entre o estudo previsto e o realizado e a evolução dos estudos com o passar do tempo.

\subsubsection{Ação}

A partir da análise dos dados coletados pela ferramenta, o usuário pode visualizar com mais facilidade suas deficiências. Caso seja necessário alterar o planejamento, a ferramenta fornece a flexibilidade para que os eventos futuros inseridos na grade de horários possam ser alterados.

\subsection{Modelagem da ferramenta Passe-me}

As principais classes geradas na elaboração da ferramenta são mostradas na Figura 2. Alguns atributos das classes e os métodos estão omitidos para melhorar a legibilidade do diagrama. O usuário (User) previamente cadastrado inclui as informações básicas necessárias para o funcionamento do sistema, conforme descrito na seção 4.1.1. Ele registra as matérias (Subject) - e as divide em grupos lógicos (SubjectGroup) - e suas fontes de estudo (StudySource).

Figura 2: Modelo de Classes

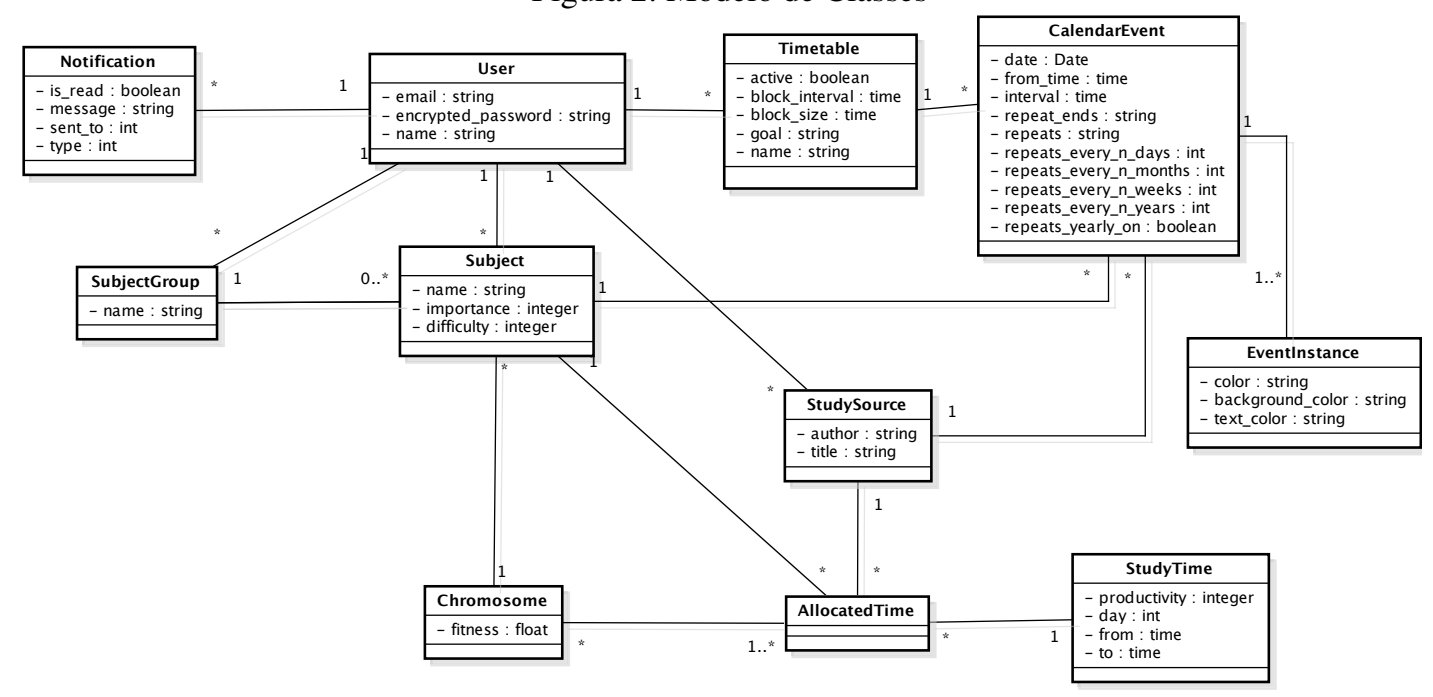

A classe CalendarEvent, associada à uma fonte de estudo (StudySource) e à uma matéria (Subject), representa um evento de estudo no calendário, criado para uma determinada grade de horários (Timetable). É por meio dessa classe que as repetições são gerenciadas, ou seja, um determinado evento pode ou não ser repetido com uma periodicidade diária, semanal, mensal ou anual. A classe EventInstance representa uma instância de um evento de estudo no calendário. Diferentemente das demais, as instâncias dos eventos não são persistidas, pois em casos de eventos que se repetem indefinidamente isto seria inviável. Assim sendo, essas instâncias são criadas dinamicamente e exibidas no calendário à medida que o período de visualização desse é alterado. Para cada grade de horários (Timetable) é registrado seu nome, objetivo, tamanho do bloco de estudos e do intervalo entre esses blocos, além da informação de se essa é ou não a grade ativa no momento.

O processo de geração da grade de horários do Passe-me faz uso de algoritmo genético. Para descrever um gene do cromossomo (Chromosome), a classe AllocatedTime é utilizada. Ela representa a alocação de uma matéria (Subject) e fonte de estudo (StudySource) a um determinado bloco de horário de estudos (StudyTime). O conjunto dessas alocações representa um cromossomo, i.e., uma solução. Os blocos de horários informados pelo usuário 
passam por um processo de normalização antes de serem enviados ao algoritmo. Esse processo divide os blocos de acordo com o tamanho do bloco de estudo e do intervalo entre blocos informados pelo usuário. Na geração da grade de horários (Timetable) é importante observar aspectos como a produtividade dos horários de estudos e a dificuldade e importância das matérias, armazenados nos atributos productivity da classe StudyTime e importance e difficulty da classe Subject, respectivamente.

O modelo de classes apresentado apoia a aplicação no uso do ciclo PDCA. As classes StudySource, Subject e SubjectGroup registram dados que fazem parte do planejamento de estudos para posterior geração da grade de horários. CalendarEvent e EventInstance apoiam as fases de execução e ação a partir da criação e conclusão de eventos de estudo e da possibilidade de ajustes de melhoria, se necessários. Além dessas, a fase de análise é apoiada pelas notificações (Notification) enviadas ao usuário, que indicam a necessidade de possíveis ajustes nos tempos dos blocos de estudos, ou na importância e dificuldade das matérias, devido, por exemplo, a muitas atividades receberem notificação de atraso de conclusão.

\subsection{Geração da grade de horários}

Em se tratando de um sistema para web, no qual é necessário que a resposta seja retornada ao usuário em um tempo aceitável, o processo de geração de grade de horários da Passe-me prioriza o desempenho no tempo de resposta em detrimento da tentativa de se obter uma grade ótima. Na geração da grade não foi adotada nenhuma técnica de paralelismo, a fim de não afetar o desempenho das requisições de outros usuários que naturalmente ocorrem em paralelo.

A população inicial de cromossomos é gerada aleatoriamente [25] de modo que cada gene recebe uma matéria e bloco de estudos. Na geração inicial da população é considerada a quantidade de cromossomos a serem gerados. Essa população é dimensionada de modo que mantenha o equilíbrio entre o desempenho proporcionado por uma população menor e a diversidade genética proporcionada por uma população maior. Nesse caso, torna-se desnecessário criar uma população $(P)$ muito grande para grades de horários que possuam um número pequeno de matérias $\left(Q_{M}\right)$ ou de blocos de horários disponíveis $\left(Q_{B H}\right)$. O tamanho da população é calculado por meio da equação 1 .

$$
P=\frac{Q_{M} Q_{B H}}{2}
$$

Em função da questão de desempenho, um número máximo de evoluções do algoritmo genético é adotado como critério para condição de parada. Esse número é dinâmico, pois há casos em que não são necessárias tantas evoluções para se chegar a uma solução satisfatória. O número máximo de evoluções é estimado por meio da equação 2, onde $N E$ é o número máximo de evoluções; $Q_{M}$ e $Q_{B H}$ são respectivamente, a quantidade de matérias e blocos de horários, e; $\sigma_{i}, \sigma_{d}$ e $\sigma_{p}$ são, respectivamente, os desvios padrões para a importância das matérias, dificuldade das matérias e produtividade dos horários.

$$
N E=\sqrt{\left(Q_{M}+Q_{B H}\right)\left(\sigma_{i} \times \sigma_{d} \times \sigma_{p}\right)}
$$

Dados dois genes $x$ e $y$ de comprimento $l g$, para o cruzamento entre eles "sorteia-se um número $p$ qualquer tal que $0<p<l g$. O primeiro filho $\mathrm{f}_{0}$ recebe todos os genes $x$ de 1 até $p$ e todos os genes $y$ de $p+1$ até $1_{y}$, e o segundo filho o inverso" [25]. A seleção dos dois genes para cruzamento é feita de modo aleatório, em que há uma probabilidade maior para seleção de cromossomos com maior aptidão. Os cromossomos gerados a partir da reprodução substituem os cromossomos com menor aptidão na população atual.

Para calcular a aptidão, considera-se as restrições e seus respectivos pesos indicadas na Tabela 1. As restrições reforçam que o processo de otimização seja feito de forma a se tentar obter uma grade de horários adequada [1]. A restrição da distribuição das matérias consiste na definição de quanto tempo deve ser alocado a cada matéria. A quantidade de tempo alocada a cada matéria é calculada a partir de sua respectiva importância, ou seja, matérias com uma importância maior obtêm maior tempo alocado. A restrição Importância da Matéria $\mathrm{x}$ Produtividade do Horário destaca a relação entre a importância de uma matéria e a produtividade do horário em que ela foi alocada. Tanto as matérias de alta importância alocadas em horários pouco produtivos e as matérias de 
baixa importância alocadas em horários muito produtivos são penalizadas. As restrições de intercalação de matérias garantem tanto que os grupos diferentes sejam intercalados, penalizando matérias diferentes e subsequentes que têm o mesmo grupo, quanto que, sejam penalizadas matérias diferentes e subsequentes que apresentam a mesma dificuldade.

Tabela 1: Restrições e seus respectivos pesos

\begin{tabular}{ll}
\hline Nome da Restrição & Peso \\
\hline Distribuição das Matérias & 10 \\
Importância da Matéria x Produtividade do Horário & 5 \\
Intercalação de Matérias de Grupos Distintos & 2 \\
Intercalação de Matérias de Dificuldades Distintas & 1 \\
\hline
\end{tabular}

\subsection{Uso da ferramenta Passe-me}

A Passe-me é uma ferramenta para web implementada em Ruby por meio do framework Ruby on Rails ${ }^{3}$, o qual segue o padrão arquitetural MVC (do inglês, Model-View-Controller). A ferramenta está disponibilizada no endereço http://passeme.com. Para acessar suas funcionalidades, o usuário deve inicialmente realizar um cadastro. O menu disponibilizado no lado esquerdo da tela permite uma fácil navegação pelas funcionalidades. Não há limite para o número de grades de horários geradas por usuário.

A Figura 3 exibe algumas telas do Passe-me indicando como o planejamento de estudos é estruturado de acordo com o ciclo PDCA. A tela (a) exibe o início do planejamento ao cadastrar as matérias necessárias ao estudos. Tais matérias podem ser trabalhadas isoladamente ou de maneira agrupada. Nessa fase são também cadastradas: as fontes de estudo, a disponibilidade de dias e horários, e a dificuldade e importância das matérias. A tela (b) apresenta a grade de horários de estudo, indicando como deve ser feita a execução do plano de estudo. As matérias nos seus respectivos horários são destacadas por diferentes cores. Gráficos como a evolução da quantidade de horas estudadas, as horas previstas versus horas realizadas e as razões para não estudar, mostrados na tela (c) apoiam a verificação do andamento dos estudos, assim como relatórios de acompanhamento do estudo. A tela (d) exibe o cadastro de um novo evento, permitindo ao usuário agir e alterar o planejamento inicial de modo a melhorá-lo para suprir as deficiências observadas.

\section{Avaliação Experimental}

Considerando-se a necessidade de oferecer uma ferramenta web, em que há a necessidade de se balancear o desempenho do algoritmo com a qualidade da solução gerada, foram realizados experimentos voltados para a análise do tempo de resposta da geração de grade de horários. Considerando a abordagem, cada bloco de horário disponível é dividido em períodos de 50 minutos, com intervalos de 10 minutos por cada bloco. Dessa forma, a avaliação foi dividida em três casos (curto, médio e longo prazo) mostrados na Tabela 2. Essa configuração foi projetada considerando-se o caso típico de uma pessoa que trabalha durante o dia e precisa se organizar para estudar nos demais horários disponíveis. No cenário de curto prazo, considerou-se uma semana de estudo com cinco matérias diferentes. No cenário de médio prazo, considerou-se duas semanas de estudo com dez matérias diferentes. Finalmente, o cenário de longo prazo, considerou-se quatro semanas de estudo com vinte matérias.

Tabela 2: Quantidade de matérias e blocos para cada caso a ser avaliado

\begin{tabular}{lccc}
\hline & Curto & Médio & Longo \\
\hline Matérias & 5 & 10 & 20 \\
Blocos de & 24 & 50 & 98 \\
Horários & & & \\
\hline
\end{tabular}

${ }^{3}$ http://rubyonrails.org/

Revista Brasileira de Computação Aplicada (ISSN 2176-6649), Passo Fundo, v. 7, n. 3, p. 17-30, out. 2015 
Figura 3: Telas da ferramenta Passe-me

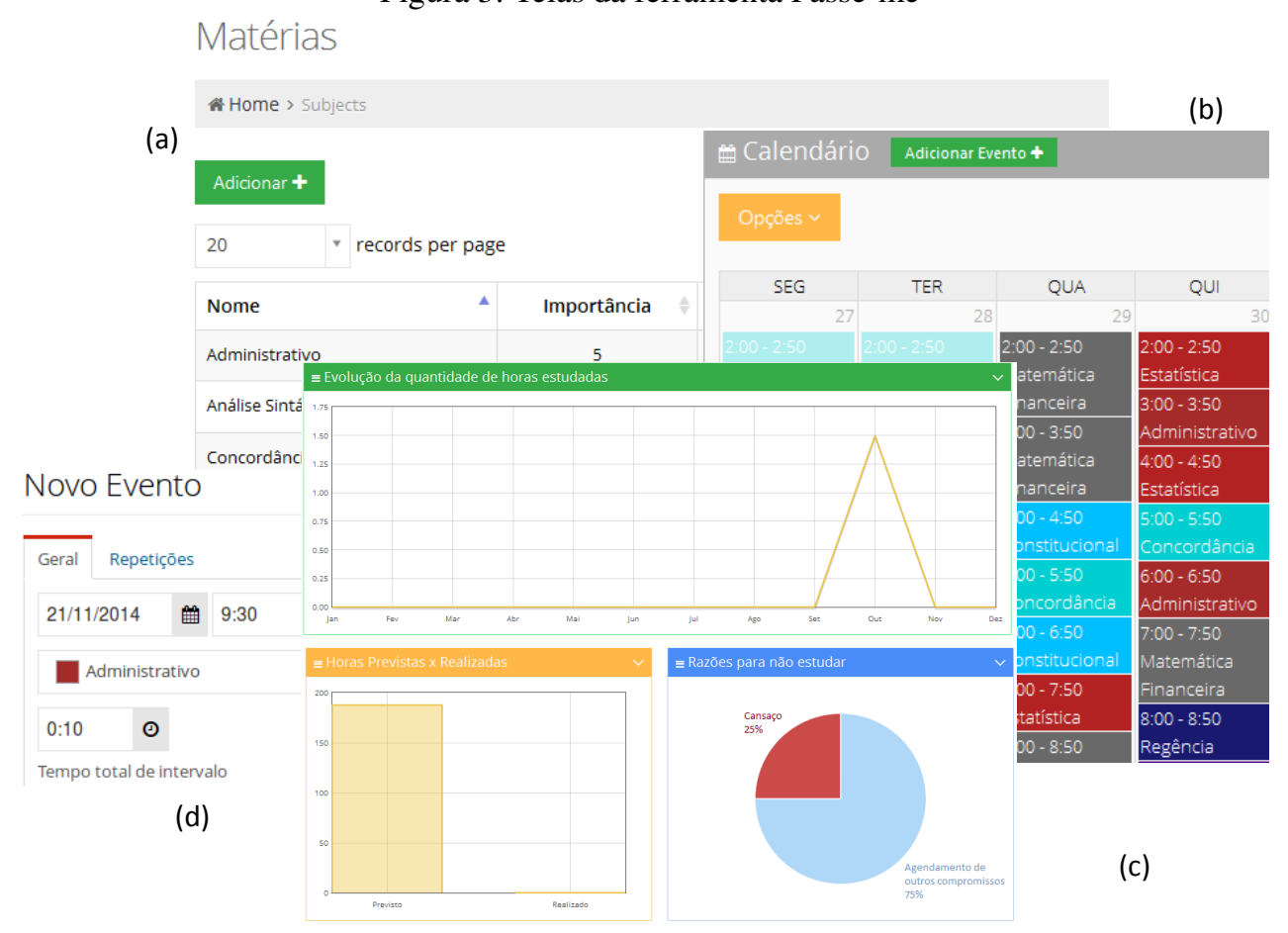

O primeiro experimento explorou a influência do tamanho da população no custo do cromossomo considerandose um número fixo de evoluções ( 25 evoluções). O algoritmo foi executado cinquenta vezes para cada número de tamanho populacional e assim foi obtida a média aritmética do conjunto de execuções. Em cada caso, houve uma redução do custo da melhor solução para cada número de tamanho populacional distinto, como pode ser visto na Figura 4.

Figura 4: Tamanho da População x Custo do Cromossomo para os cenários de curto, médio e longo prazo

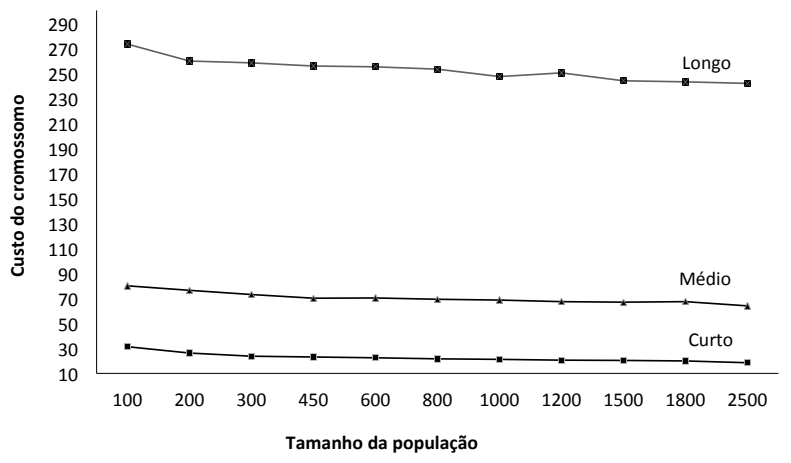

O segundo experimento verificou a influência do número de evoluções para um número fixo de cromossomos ( 2500 cromossomos). A chamada do algoritmo foi feita 50 vezes e foi obtida a média aritmética do conjunto de chamadas para cada evolução. A Figura 5 retrata a redução do custo da melhor solução para cada número de evoluções distinto.

A variação no tamanho da população apresentou melhores resultados no cenário de curto prazo e resultados menos satisfatórios nos cenários de médio e longo prazo. Os resultados melhoraram continuamente com o aumento do número de evoluções para todos os três cenários. Houve uma melhoria mais acentuada do custo da solução entre 
Figura 5: Número de Evoluções x Custo do Cromossomo para os cenários de curto, médio e longo

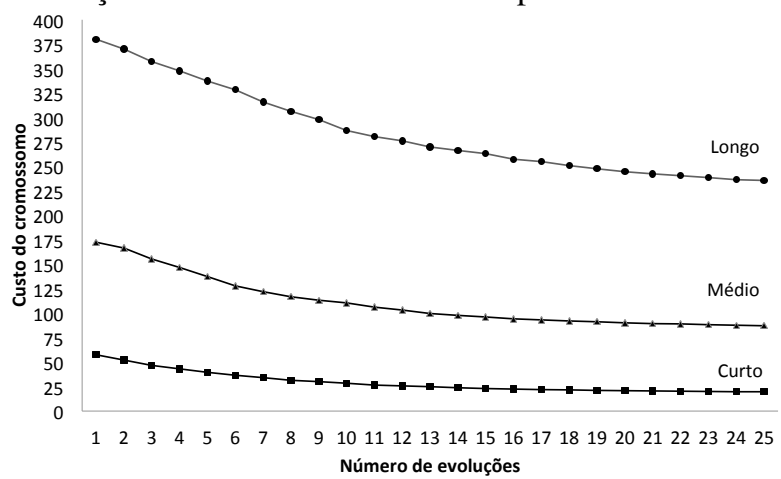

a primeira e décima evolução, apresentando também melhores resultados no cenário de curto prazo. É possível observar que no geral o número de evoluções teve um impacto maior na convergência positiva das soluções. Em termos de desempenho isto também fica visível. Um aumento do tamanho populacional degrada o desempenho do algoritmo de forma muito mais significativa do que um aumento no número de evoluções na mesma proporção.

O terceiro experimento avaliou o cálculo automático do número de gerações. O experimento foi avaliado para o cenário de médio prazo com uma composição de quantidade de matérias e blocos de horários considerandose as matérias da Tabela 3. Foram utilizados os parâmetros de configuração expostos na seção 4.3. A importância e a dificuldade de uma matéria na ferramenta consistem em um grau que varia segundo uma escala likert de 1 a 5 . O cenário de médio prazo também conta com 50 blocos de horários de 50 minutos, conforme exposto anteriormente na Tabela 2. O desvio padrão para a produtividade desses horários é de 1,4177.

Dessa maneira, ao aplicar as equações 1 e 2 no cenário de médio prazo foram encontrados os resultados mostrados em 3 e 4 para obter o tamanho da população e o número de evoluções, respectivamente. Com esses parâmetros, foi efetuada novamente a chamada do algoritmo 50 vezes e assim obtida a média aritmética do conjunto de chamadas para cada geração. A relação entre o número de evoluções e custo do cromossomo é mostrado na Figura 6, considerando-se a população igual a 250.

$$
\begin{gathered}
P=\frac{Q_{M} Q_{B H}}{2}=\frac{10 \times 50}{2}=250 \\
N E=\sqrt{\left(Q_{M}+Q_{B H}\right)\left(\sigma_{i} \times \sigma_{d} \times \sigma_{p}\right)}=\sqrt{(10+50)(1,4967 \times 1,5 \times 1,4177)} \cong 14
\end{gathered}
$$

Tabela 3: Dados das matérias utilizadas no exemplo de aplicação do algoritmo

\begin{tabular}{cccc}
\hline Matéria & Importância & Dificuldade & Grupo \\
\hline Mat. - Probabilidade & 4 & 3 & 1 \\
Mat. - Estatística & 4 & 4 & 1 \\
Mat. - Financeira & 4 & 2 & 1 \\
Mat. - Álgebra Linear & 1 & 4 & 1 \\
Por. - Concordância & 2 & 4 & 1 \\
Por. - Regência & 5 & 1 & 1 \\
Por. - Análise sintática & 1 & 5 & 2 \\
Por. - Interpretação & 4 & 5 & 2 \\
Dir. - Administrativo & 5 & 5 & 2 \\
Dir. - Constitucional & 5 & 1 & 2 \\
\hline
\end{tabular}

Revista Brasileira de Computação Aplicada (ISSN 2176-6649), Passo Fundo, v. 7, n. 3, p. 17-30, out. 2015 
O tempo de resposta para o terceiro experimento apresentou valores aceitáveis para uma ferramenta web. Usando uma máquina com configuração Intel Core i5 460M de 2,53 GHz, 4GB de RAM e sistema operacional Linux Ubuntu 12.04, o tempo de resposta foi de apenas 5 segundos considerando-se que apenas um núcleo de um processador é utilizado a cada processo de otimização.

Figura 6: Número de Evoluções x Custo do Cromossomo para o exemplo de aplicação do algoritmo

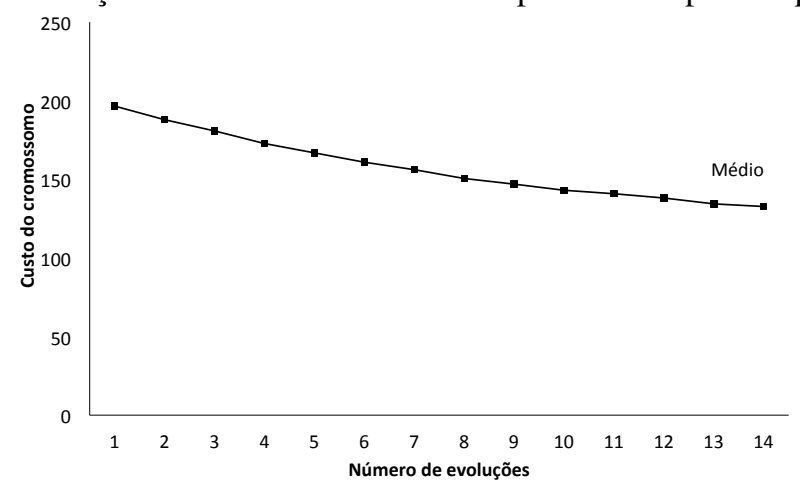

\section{Conclusão}

Este trabalho apresenta a ferramenta Passe-me que é voltada para planejamento de estudos, mais especificamente para cenários de concursos públicos. A estruturação da Passe-me foi concebida na perspectiva de um projeto de estudos baseado no ciclo PDCA. Essa estruturação da ferramenta viabiliza que o estudante reduza a incerteza do seu projeto de estudo ao organizar a sua grade de horários. A ferramenta possibilita gerenciar e catalogar os materiais necessários para atingir o escopo do projeto de estudo; monitorar o andamento do projeto de acordo com o cronograma inicial, fornecendo flexibilidade para possíveis desvios; e controlar o tempo gasto em cada etapa. Essa gerência faz com que sistematicamente a grade de horários seja revalidada a partir das restrições definidas pelo usuário e a evolução dos seus estudos. Dessa forma, em se tratando de uma ferramenta web, o tempo de resposta para uma requisição é vital para o bom funcionamento da mesma, sendo assim, o processo de geração da grade de horários não pode impactar negativamente no funcionamento da ferramenta.

Para a geração da grade de horários, foi utilizada uma abordagem baseada em algoritmos genéticos que oferece versatilidade para as definições das restrições indicadas pelos estudantes. Em função disso, o trabalho propõe um cálculo dinâmico para o tamanho da população e o número de evoluções a serem adotados no processo de otimização. Foi realizada uma avaliação experimental para avaliar o processo de geração de grades de horários considerando-se cenários de curto, médio e longo prazo de estudo. Os resultados experimentais indicaram que foi possível alcançar um equilíbrio entre o tempo gasto no processo de otimização da grade de horários e a geração da tabela de horários.

Como trabalhos futuros, pretendemos realizar uma avaliação experimental considerando o acompanhamento de um conjunto de alunos do ensino médio e da graduação durante um bimestre para verificarmos se a ferramenta traz benefícios no planejamento e acompanhamento dos seus estudos como preparação para os seus exames. A ferramenta Passe-me encontra-se disponível para uso geral em http://passeme.com.

\section{Agradecimentos}

Os autores agradecem a FAPERJ e CNPq pelo financiamento parcial do trabalho.

\section{Referências}

[1] PINHEIRO, R. N. Como se Preparar para Concursos Públicos com Alto Rendimento. 1. ed. Brasil: Método,

Revista Brasileira de Computação Aplicada (ISSN 2176-6649), Passo Fundo, v. 7, n. 3, p. 17-30, out. 2015 
2010.

[2] Mundo Carreira. Aumento de vagas para concursos públicos no Brasil. 2014. Disponível em: <http: //www.mundocarreira.com.br/concursos-publicos/aumento-de-vagas-para-concursos-publicos-brasil/>. Acesso em: 30 out. 2015.

[3] FENAPEF. Concursos públicos faturam $R \$ 50$ bi. 2014. Disponível em: <http://fenapef.org.br/fenapef/ noticia/index/38064>. Acesso em: 30 out. 2015.

[4] MEIRELlES, A. Como Estudar Para Concursos. 3. ed. Brasil: Método, 2014.

[5] STAFF, G. The Problem Solving Memory Jogger: Seven Steps to Improved Processes. 2. ed. United States: GOAL/QPC, 2011.

[6] CARTER, C. J.; BISHOP, J.; KRAVITS, S. L. Keys to College Studying: Becoming an Active Thinker. 2. ed. Upper Saddle River, N.J.: Prentice Hall, 2006.

[7] MOORE, S. et al. The Ultimate Study Skills Handbook. 1. ed. Maidenhead, England: Open University Press, 2010.

[8] TALBOT, C. Studying at a Distance: A guide for students. 3. ed. Berkshire, England: Open University Press, 2010 .

[9] WONG, L. Essential Study Skills. 7. ed. Australia; United States: Cengage Learning, 2011.

[10] CHIAVENATO, I. Introdução à Teoria Geral da Administração. 9. ed. São Paulo: Manole, 2014.

[11] MAXIMIANO, A. C. A. Introdução à Administração. 1. ed. Brasil: Atlas, 2011.

[12] INSTITUTE, P. M. Um Guia do Conhecimento em Gerenciamento de Projetos. 5. ed. Brasil: Project Management Institute, 2013.

[13] PINHEIRO, R. N. Concursos Públicos e Exames Oficiais. Preparação Estratégica, Eficiente e Racional. 1. ed. Brasil: Atlas, 2009.

[14] DOUGLAS, W. A Arte da Guerra para Provas e Concursos. 1. ed. Brasil: Elsevier Técnico, 2009.

[15] DOUGLAS, W. Como Passar em Provas e Concursos. 28. ed. Brasil: Impetus, 2013.

[16] BOSE, T. K. Total Quality of Management. 1. ed. India: Pearson, 2010.

[17] WALSH, R. Time Management: Proven Techniques for Making Every Minute Count. 2. ed. [S.1.]: Adams Media, 2008.

[18] BROWNLEE, J. Clever Algorithms: Nature-Inspired Programming Recipes. 1. ed. United States: lulu.com, 2012.

[19] ABBASZADEH, M.; SAEEDVAND, S. A Fast Genetic Algorithm for Solving University Scheduling Problem. IAES International Journal of Artificial Intelligence (IJ-AI), v. 3, n. 1, p. 7-15, mar. 2014.

[20] NUNTASEN, N.; INNET, S. A Novel Approach of Genetic Algorithm for Solving University Timetabling Problems: A Case Study of Thai Universities. In: Proceedings of the 7th Conference on Applied Computer Science. Stevens Point, Wisconsin, USA: World Scientific and Engineering Academy and Society (WSEAS), 2007. (ACS’07), p. 246-252.

[21] MOUSA, H.; EL-SISI, A. Design and implementation of course timetabling system based on genetic algorithm. In: 2013 8th International Conference on Computer Engineering Systems (ICCES). Jilin, China: [s.n.], 2013. p. 167-171.

[22] SONAWANE, M. P. A.; RAGHA, L. Hybrid Genetic Algorithm and TABU Search Algorithm to Solve Class Time Table Scheduling Problem. International Journal of Research Studies in Computer Science and Engineering, v. 1, p. 19-26, 2014.

Revista Brasileira de Computação Aplicada (ISSN 2176-6649), Passo Fundo, v. 7, n. 3, p. 17-30, out. 2015 
[23] CABAlLERO-CABALLERO, S. et al. A Hybrid Simulated Annealing-Genetic Algorithm for Course Time Tabling Problem. International Journal of Recent Technology and Engineering, v. 3, p. 65-70, 2014.

[24] Tuctor. Gerenciador de Estudos. 2014. Disponível em: <http://www.tuctor.com>. Acesso em: 30 out. 2015.

[25] GOLDBERG, D. E. Genetic Algorithms in Search, Optimization and Machine Learning. 1. ed. Boston, MA, USA: Addison-Wesley Longman Publishing Co., Inc., 1989. 